\title{
Non-Tuberculous Mycobacteria Recovered from Suspected TB Cases in Namwala District of Zambia
}

\author{
Ngula Monde ${ }^{1,2}$, Musso Munyeme ${ }^{2}$, Adrian Muwonge ${ }^{3}$, John Bwalya Muma ${ }^{2}$, Sydney Malama ${ }^{4 *}$ \\ ${ }^{1}$ Department of Biomedical Sciences, Tropical Diseases Research Center, Ndola, Zambia \\ ${ }^{2}$ Department of Disease Control, School of Veterinary Medicine, University of Zambia, Lusaka 10101, Zambia \\ ${ }^{3}$ Division of Genetics and Genomics, Roslin Institute, The Royal Dick School of Veterinary Studies, The \\ University of Edinburgh, Easter Bush, Midlothian, EH259RG, Scotland, UK \\ ${ }^{4}$ Health Promotions Unit, Institute of Economic and Social Research, University of Zambia, Lusaka, Zambia \\ *Corresponding Author: Sydney Malama, Health Promotions Unit, Institute of Economic and Social \\ Research, University of Zambia, Lusaka, Zambia, Email: sydneymalama1971@gmail.com
}

\begin{abstract}
Non-tuberculous Mycobacteria (NTM) and Mycobacterium tuberculosis complex (MTBC) belong to Mycobacteria genus and are known to cause diseases in humans and animals. In Zambia, Non tuberculous Mycobacteria are gaining recognition as pathogens of public health significance. However, there is lack of laboratory infrastructure at every $T B$ diagnostic facility to identify and speciate these organisms for better patient management. Therefore, this study is aimed at identifying NTM among TB suspects in Namwala District of Zambia. This was a cross-sectional study in which 153 individuals with suspected TB were sampled from four health facilities in Namwala district. Sputum samples were also collected from the suspected TB patients. Standard TB culture methods were employed to isolate Mycobacteria spp and later $16 S-23 S$ internal transcribed spacer region Sequencing was employed to characterize NTM. Seven (7, 4.6\%) NTM species were identified from humans and included, M. arupense. Mycobacterium avium and Mycobacterium fortuitum. This study has shown the recovery of NTM among TB suspected patients. This is of concern as most of these cases are incorrectly diagnosed as TB and wrongly started on anti-TB therapy.
\end{abstract}

Keywords: Namwala, Mycobacteria, Sequencing, Zambia

\section{INTRODUCTION}

The genus Mycobacterium consists of over 140 known species and these are classified as nontuberculous Mycobacteria (NTM) and mycobacteria belonging to Mycobacterium tuberculosis complex (MTBC), the causative agent of pulmonary tuberculosis (TB) (Brosch et al., 2002;Tortoli, 2006). Mycobacterium is a single genus within the family Mycobacteriaceae, under the order Actinomycetales, class Actinomycetes and phylum Actinobacteria (Wayne and Kubica, 1986).

Mycobacteria are aerobic, non-motile organisms which exhibit acid- alcohol fastness. They contain a lipid rich, hydrophobic cell wall, which is thicker than other bacterial cell walls (Ray and Ryan, 2004). The thickness and structure of the cell wall makes mycobacteria impermeable to hydrophilic nutrients and resistant to heavy metals, disinfectants, and antibiotics (Jarlier and Nikaido, 1994).
The non-tuberculous Mycobacteria (NTM) include those Mycobacterium species that are not members of the Mycobacterium tuberculosis complex (MTBC), the causative agent of pulmonary tuberculosis (TB) and Mycobacterium leprae (Asiimwe et al., 2013; Malama et al., 2014).They are ubiquitous in the environment, animals, birds, soils and occasionally in drinking water(Muwonge et al., 2012; Ricketts et al., 2014; Velayati et al., 2014). The environment is reported to be the primary source of infection of these mycobacteria for human populations. Humanto-human transmission of NTM is generally uncommon, but there is evidence of transmission of certain NTM species such as Mycobacterium kansasii(Ricketts et al., 2014). NTM have also been recovered from meat, fish, dairy products, fruits, vegetables and especially unpasteurized milk, suggesting a zoonotic potential for these bacteria (Konuk et al., 2007). 
There are 172 different species of NTM but the most important and potentially pathogenic of these are $M$. avium, $M$. intracellulare, $M$. kansasii, M. xenopi, and M. abscessus (Kankya et al., 2011). These organisms are capable of causing pulmonary disease, disseminated disease and localized lesions, mostly in immuno-compromised and competent individuals (Katoch, 2004). Pulmonary disease is the most frequently encountered and has been reported to account for up to $94 \%$ of cases of NTM disease (Panagiotou et al., 2014). People living with the Human Immunodeficiency Virus (HIV) and Acquired Immunodeficiency Syndrome (HIV/AIDS), represent some of the most vulnerable populations to NTM infection, as well as a higher risk for complications and poor disease outcomes. Those receiving immunosuppressive therapy secondary to organ transplantation, cancer, autoimmune disease and those with diabetes mellitus may also be more susceptible to NTM as compared with the general population (Akbar et al., 2015).

Risk factors for NTM infections have been documented in literature (Falkinham, 2009), and these may be divided into underlying medical conditions, living and work environment as well as patient demographic features. Underlying medical conditions provides the most powerful risk factor for NTM infection and these may be divided into destruction of local pulmonary defenses and generalized immune defects, for example Cystic Fibrosis (CF) and HIV, respectively. Pre-existing lung disease, such as pneumoconiosis, chronic obstructive pulmonary disease (COPD), bronchiectasis, prior tuberculosis, pulmonary alveolar proteinases, and esophageal motility disorders are also linked to NTM infection (Katoch et al., 2007; Faria et al., 2015). Alcohol abuse, diabetes mellitus, malignancy and smoking have also been identified as potential risk factors (Katoch et al., 2007).

Although members of the MTBC are largely known to cause the majority of the mycobacterial infections worldwide, NTM are comparatively recovered in higher proportions from patients presenting with typical tuberculosis clinical signs (Kankya et al., 2011).Non-tuberculous Mycobacteria infection share clinical and radiological similarities with Mycobacterium tuberculosis complex, the causative agent of $\mathrm{TB}$, hence the need for species differentiation in order to distinguish NTM disease from MTBC in individuals suggestive of having TB (Kapata et al., 2015).
In Zambia, Acid Fast Bacilli (AFB) smear microscopy is routinely used to diagnose TB. However, this method does not distinguish between tuberculosis and NTM disease.

Therefore, NTM patients seeking care in health facilities could potentially be misdiagnosed and incorrectly treated as TB (Aliyu et al, 2013), since all smear positive patients are placed on anti-TB therapy. This could consequently lead to treatment failures and later classified as MDR-TB because patients with NTM disease require longer treatment duration and at times treatment varies according to the species involved. This mismanagement of Patients may have a negative impact on the health status of the individual and eventually put additional cost to the health system (Kapata et al., 2015).This study aimed at identifying NTM among TB suspects in Namwala District of Zambia.

\section{MATERIALS AND MeTHOdS}

\subsection{Study Site}

The study was conducted in Zambia in the rural district of Namwala. The district is situated in the Southern Province of Zambia and is one of the districts with a large number of Pastoral farmers. Four sampling areas were selected and these are; Namwala central, Maala, Kabulamwanda and Chitongo. Namwala is one of the districts in Zambia with the highest TB prevalence in both animals and humans (Malama et al., 2014c; Munyeme et al., 2009). It covers an estimated total area of about 10,000 square kilometers and lies between latitudes 15 and $17^{\circ} \mathrm{S}$ of the equator and longitude 25 and $27^{\circ} \mathrm{E}$. The greater area of its traditional land is covered by the Kafue Flood plains of the Kafue River. This offer nutritive varieties of rich lush green grass for both cattle and wildlife for a greater part of the year than the surrounding Savannah woodlands (Munyeme et al., 2010). Namwala district supports approximately 30000 herds of cattle and approximately 44,000 Kafue lechwe(Malama et al., 2014c) and agriculture is the main economic activity. Humans and animals commonly share the same micro environments such as water drinking points, especially in dry seasons (Phiri, 2006), increasing the possibility of interspecies disease transmission or contamination of water sources, which could potentially lead to a zoonotic transmission to humans (Katale et al, 2014).

\subsection{Study Design and Sampling}

This was a cross-sectional study where sputum samples from human adult ( $\geq 15$ years old) TB 
suspected patients and water samples were collected and analyzed. Two sputum samples were collected from each patient with TB symptoms (which included, coughing of than two weeks, loss of appetite, night sweats) who were seeking medical attention at four local health facilities in the four study areas. The health facilities comprised of Namwala District Hospital, Maala Rural Health Centre, Kabulamwanda Rural Health Centre and Chitongo Rural Health Centre. A semistructured questionnaire was administered to study participants who consented by signing a participant consent form. This was followed by submission of sputum samples. The questionnaire was administered in English and Tonga.

\subsection{Isolation and Identification of NTM}

NTM were isolated using Lowestein Jensen (LJ)by standard microbiological procedures. The isolates were then subjected to PCR amplification and DNA sequencing of the 16S23SrRNA(ITS) region with primers Sp1 (5'ACC TCC TTT CTAAGG AGC ACC- $3^{\prime}$ ) and Sp2 (5'-GAT GCT CGC AACCAC TAT CCA$\left.3^{\prime}\right)$. The obtained sequences were aligned using MEGA version 7and the alignments were then blasted against the NBCI database with Mycobacterium taxid 85007 as the reference organism. The strain name with the highest E.value and identity hit and score was chosen.

\subsection{Data Analysis}

The Data from the questionnaire, biodata sheet and laboratory analysis were entered in Excel Spread sheet and subsequently imported to STATA version 12(STATA Corp, College Station, Texas) for final descriptive and statistical analyses. Proportions of NTM from humans and water were computed. Measures of association and factor analysis for the presence of NTM in suspected TB cases was done using a univariate and multivariate logistic regression model in $\mathrm{R}$. The logistic regression and variable selection was done by forward selection method using variables that had $p$ value less than 0.25 on a univariate analysis. Model validation and fit was done using the standard post estimation statistics.

\section{ReSUltS}

Out of the 153 study participants, $47.1 \%$ (95\% CI: 39.10-55.10) were males and 52.9\% (95\%CI: 44.9-60.9) were females. About 60.1\% of the study population was aged between 21 and 40 years. The median age and interquartile range (IQR) was 36 (28 to 41 ) years. The majority (81.7) of the population were farmers by occupation and $75.8 \%$ were married.

Table1. Show the summary characteristics of the suspected TB cases in Namwala district

\begin{tabular}{|c|c|c|c|}
\hline Variable & No. $(\%)$ & $\begin{array}{ll}\text { No. } & \text { of } \\
\text { NTM }\end{array}$ & $\begin{array}{l}\mathrm{p}- \\
\text { value }\end{array}$ \\
\hline \multicolumn{4}{|l|}{ Gender } \\
\hline \multirow{2}{*}{$\begin{array}{l}\text { Male } \\
\text { Female }\end{array}$} & $72(47.1)$ & 1 & \multirow[t]{2}{*}{0.1209} \\
\hline & $81(52.9)$ & 6 & \\
\hline \multicolumn{4}{|l|}{ Age group } \\
\hline \multirow{4}{*}{$\begin{array}{l}0-20 \\
21-40 \\
41-60 \\
61+\end{array}$} & $6(3.9)$ & - & \multirow[t]{4}{*}{0.788} \\
\hline & $92(60.1)$ & 5 & \\
\hline & $50(32.7)$ & 2 & \\
\hline & $5(3.3)$ & - & \\
\hline \multicolumn{4}{|l|}{ Occupation } \\
\hline Farmer & $125(81.7)$ & 7 & 1.000 \\
\hline \multicolumn{4}{|c|}{ Marital Status } \\
\hline \multirow{3}{*}{$\begin{array}{l}\text { Married } \\
\text { Single } \\
\text { Divorced }\end{array}$} & $116(75.8)$ & 5 & \multirow[t]{3}{*}{0.4133} \\
\hline & $35(22.9)$ & 1 & \\
\hline & $2(1.3)$ & 1 & \\
\hline \multicolumn{4}{|l|}{ HIV Status } \\
\hline \multirow{2}{*}{$\begin{array}{l}\text { Positive } \\
\text { Negative }\end{array}$} & $82(53.6)$ & 3 & \multirow[t]{2}{*}{0.7049} \\
\hline & $71(46.4)$ & 4 & \\
\hline \multicolumn{4}{|c|}{ Clinical Symptoms } \\
\hline \multirow{6}{*}{$\begin{array}{l}\text { Cough } \\
\text { Headache } \\
\text { Night sweats } \\
\text { Fever } \\
\text { Chill } \\
\text { Fatigue }\end{array}$} & $153(100)$ & 7 & 0.2409 \\
\hline & $86(56.2)$ & 2 & 0.2396 \\
\hline & $88(57.1)$ & 6 & 0.4631 \\
\hline & $85(55.6)$ & 5 & 0.3177 \\
\hline & $61(39.9)$ & 5 & 0.1157 \\
\hline & $116(75.8)$ & 5 & 0.676 \\
\hline
\end{tabular}

Of the153 individuals with TB symptoms, 7(4.6\%) were found to have NTM with $M$. arupense $2 \%(3 / 153)$ being the most prevalent species. Ten (6.5\%) were identified as Mycobacterium tuberculosis complex.

Table2. NTM species isolated from suspected TB patients and various water sources in Namwala district

\begin{tabular}{|l|l|l|l|}
\hline NTM species & $\mathrm{N}$ & Frequecy(\%) & 95\% CI \\
\hline Humans (N=153, $\mathrm{n}=7)$ & \multicolumn{3}{|l|}{} \\
\hline M. arupense & 3 & 2.0 & $0-4.2$ \\
\hline M. abscesus & 1 & 0.7 & $0-1.9$ \\
\hline M. avium & 1 & 0.7 & $0-1.9$ \\
\hline M. fortuitum & 1 & 0.7 & $0-1.9$ \\
\hline M. nebraskense & 1 & 0.7 & $0-1.9$ \\
\hline $\begin{array}{l}\text { Mycobacterium } \\
\text { tuberculosis } \\
\text { complex }\end{array}$ & 10 & 6.5 & $0.02-0.1$ \\
\hline
\end{tabular}

$\mathbf{n}=$ Number of NTM species

The factor analysis for harbouring NTM in humans shows that Female suspected TB cases are $\sim 12$ time more likely to have NTM when compared to male suspected TB cases. On the other hand, suspected TB patients that presented with chills and night sweats were less likely to have NTM recovered from their sputum. 
Table3. Multi-variable logistic regression model showing the factors associated with NTM in TB suspected patients

\begin{tabular}{|c|c|c|c|}
\hline Factor & Level & $\begin{array}{l}\text { Odds Ratio } \\
(\mathrm{CI}=95 \%)\end{array}$ & $\begin{array}{l}\text { P- } \\
\text { value }\end{array}$ \\
\hline Gender & Female & $\begin{array}{l}11.74 \\
(1.46- \\
278.7)\end{array}$ & 0.048 \\
\hline $\begin{array}{l}\text { Night } \\
\text { sweats }\end{array}$ & $\begin{array}{l}\text { No night } \\
\text { sweats }\end{array}$ & $\begin{array}{l}0.09 \\
(0.003- \\
0.75)\end{array}$ & 0.05 \\
\hline Chills & No chills & $\begin{array}{l}0.07 \\
(0.005- \\
0.48)\end{array}$ & 0.015 \\
\hline Headaches & $\begin{array}{l}\text { No } \\
\text { headaches }\end{array}$ & $\begin{aligned} & 8.3(1.19 \\
&-92.91)\end{aligned}$ & 0.048 \\
\hline $\begin{array}{l}\text { Source of } \\
\text { milk }\end{array}$ & $\begin{array}{l}\text { Other } \\
\text { farmers }\end{array}$ & $\begin{array}{l}1.916 \\
(0.318- \\
13.0)\end{array}$ & 0.479 \\
\hline
\end{tabular}

$H L=7.49, p$-value $0.4848, A U C=0.886$

\section{DISCUSSION}

The World Health Organization through its manual of mycobacterial diseases recognizes the public health importance and complexity in managing NTM infections in human population (WHO, 1991). These infections have become more common in both immune-compromised and immune competent individuals globally (Ahmed et al., 2013), however most of the information about their incidence and prevalence has come from developed countries. Given the co-occurrence of HIV/AIDS and tuberculosis which is compounded with compromised municipal and hygiene systems in developing countries, it is critical to understand the dynamics of NTM in resource limited settings like Namwala. The weak diagnostic infrastructure in such settings means that false positive TB cases due to NTM triage are unnecessary commenced on unspecific TB treatment. This could be contributing to the current bottleneck caused by antibiotic drug resistance (Ahmed et al, 2013).

This study observed that NTM was mostly recovered from suspected TB cases whose occupation was farming. This could possibly due to overtime exposure to NTM contaminated soil and water as agriculture is the main economic activity in Namwala district(Malama et al., 2014c).In the present study NTM from humans in Namwala district were isolated and sequenced. This observation was also made in a study done in Shanghai China by $\mathrm{Wu}$ et al (2014).

The factor analysis in this study reveals that females suspected TB cases are 12 times more likely to have NTM than their male counter parts. A population- based study done by Cassidy et al (2007), Oregon, USA, found that NTM pulmonary disease occurs more frequently in women than in men and NTM disease was also strongly associated with advanced aged. Our findings were also in agreement with literature, which has highlighted the changing epidemiology of NTM disease to affecting more women regularly than men (Griffith et al., 2007; Kim et al., 2008). The high incidences of NTM in female TB suspects in our study could partly be attributed to female's high medical care seeking behavior which leads to high chances of them being diagnosed with the disease (WHO, 2007).

Individuals with night sweats and chills were less likely to have NTMs. This would seem plausible given that night sweats and chills are typical clinical presentations for TB caused by MTCs. Constitutional symptoms such as weight loss, fever, night sweats are less frequent occurring in 30 to50\% of patients and are indicative of advanced disease (Griffith et al, 2007; VanIngen at al 2009; Gopinath et al., 2010). Our study clearly shows that headache is not a constitutional symptom of having pulmonary NTM infection and it agrees well with literature.

The most common NTM organism identified from the patients was Mycobacterium arupense. To the best of our knowledge this is the first study in Zambia to report the isolation of Mycobacterium arupense in human sputum samples. However, a study conducted in the USA reported Mycobacterium arupense in TB suspected cases (Cloud et al, (2002). It has also recently been reported as an emerging cause of Tenosynovitis in Chicago (Lopez et al., 2016). On the other hand, these infections have been reported at clinical level elsewhere Masaki et al, (2006), Tsai et al, (2008), and Neonakis et al, (2010). In India, Mycobacterium arupense has been reported to cause pulmonary infection with exceptional management challenges because of antibiotic resistance. The isolation of this organism in 3 of the 153 suspected TB cases in our study is of concern, not only with regard to diagnostics but also management of these infections. There is no evidence from this study to suggest that this species is acquired by human-to-human transmission though drinking water has been suggested to be a reservoir for many pathogenic and potentially pathogenic NTM (Falkinham et al., 2001; Primm et al., 2004; Thomson et al., 2013). 


\section{CONCLUSION}

This study has shown the recovery of NTM among TB suspected patients. These findings suggest that such individuals are likely to be wrongly started on TB therapy which is likely to present challenges in case management as well as antibiotic resistance. The study utilized a small sample size due to limited resources. Its however, recommended that a larger sample size be used in future studies for epidemiological inferences and conclusions. Further, diagnosis of TB in Zambia should include molecular methods such $16 \mathrm{~S}$ sequencing, Deletion analysis, Spoligotyping and Multi locus variable analysis.

\section{ACKNOWLEDGEMENT}

This work was supported by funds from NORAD/NORHEAD through the CAPAZOMANINTECO project from which Ngula Monde was a scholarship recipient. The authors would like to thank JICA and staff at virology laboratory, School of Veterinary Medicine, University of Zambia and Tropical Diseases Research Centre, TB reference laboratory for their assistance in laboratory work. We are also grateful to field assistants in Namwala district.

\section{ETHICAL APPROVAL}

Ethical clearance to conduct the study was sought and granted from Excellence in Research Ethics and Science converge (ERES) IRB (Ref. No. 2015-Aug-002). Approval to conduct the study in Namwala district was granted by the National Health Research Authority, Ministry of Health in Zambia. The study did not pose any risk to the participants and confidentiality was maintained.

\section{AUTHOR CONTRIBUTION}

NM, collected samples, analyzed the data and drafted the manuscript, MM, analyzed the data and supervised field and laboratory work, AM, analyzed data, JBM, analyzed data, and overall supervision of the work, SM, conceptualized the study, drafted the manuscript and revised the manuscript

\section{REFERENCES}

[1] Ahmed, I., Jabeen, K., Hasan, R., 2013b. Identification of non-tuberculous mycobacteria isolated from clinical specimens at a tertiary care hospital: a cross-sectional study. $B M C$ Infectious Diseases, 13(1), 1- 7

[2] Akbar, A., Derakhshaninezhad, Z., Mirsaeidi, Ml., 2015. Nontuberculous mycobacteria in Middle East: Current situation and future challenges. International Journal of Mycobacteriology 12, 1-11.

[3] Aliyu, G., El-Kamary. S.S., Abimiku, A., Brown. C., Tracy, K., Hungerford, L., Blattner, W., 2013. Prevalence of Non-Tuberculous Mycobacterial Infections among Tuberculosis Suspects in Nigeria., 8(5), 1-7.

[4] Asiimwe, B.B., Bagyenzi, G.B., Ssengooba, W.,Mumbowa, F., Wajja, A., Mayanja-kiiza, H., Wbudeya, E., Kallenius, G., Joloba, M., 2013. Species and genotypic diversity of nontuberculous mycobacteria isolated from children investigated for pulmonary tuberculosis in rural Uganda. BMC Infectious Diseases 13, 88

[5] Buijtels, P.C.A.M., Petit, L. C. P., Verbrugh, H. A., Belkum, A.V., Soolingen, D.V., 2005. Isolation of Nontuberculous Mycobacteria in Zambia : Eight Case Reports. , 43(12), 60206026.

[6] Buijtels, P.C.A.M. Sande, A.B. M., Petit, L. C. P., Verbrugh, H. A., Belkum, A.V., Soolingen, D.V., 2009. Nontuberculous Mycobacteria, Zambia, emerging Infectious Diseases 15(2). $242-249$

[7] Cassidy, P. M., Hedberg, .H., Saulson, A., McNell, E., Winthrop, K.L., 2009. Nontuberculous Mycobacterial Disease Prevalence and Risk Factors: A Changing Epidemiology. Clinical infectious Diseaes 49, $124-129$

[8] Chanda-kapata, P., Kapata, N., Klinkenberg, E., Mulenga, L., Tembo, M., Katemangwe, P., Sunkutu, V., Mwaba, P., Grobusch, M., 2015. Non-tuberculous mycobacteria ( NTM ) in Zambia : prevalence, clinical, radiological and microbiological characteristics. BMC Infectious Diseases, 1-7.

[9] Falkinham, J.O., 1996. Epidemiology of Infection by Nontuberculous Mycobacteria, Clinical and Microbiology Reviews, 9(2), 177215.

[10] Falkinham, J.O., Norton, D. C., LeChevallier, M. W., 2001. Factors Influencing Numbers of Mycobacterium avium , Mycobacterium intracellulare, and Other Mycobacteria in Drinking Water Distribution Systems, Applied and Environmental Microbiology 67(3),1225 1231.

[11] Falkinham, J.O., 2009. Surrounded by mycobacteria : nontuberculous mycobacteria in the human environment, Journal of Applied Microbiology, 107, 356-367.

[12] Faria, S., Joao, I. \& Jordao, L., 2015. General Overview on Nontuberculous Mycobacteria, Biofilms , and Human Infection, Journal of Pathogens 2015, 1- 10

[13] Gopinath K., Singh S., 2010. Non-Tuberculous Mycobacteria in TB-Endemic Countries: Are 
WeNeglecting the Danger? PLoS Neglected Tropical Diseases 4(4): e615. doi:10.1371/journal.pntd. 000061

[14] Griffith, D.E., Aksamit, T., Brown-Elliott B. A., Catanzaro A., Daley. C, Gordin, F., Holland, S. T., Horsburgh, R., Huitt, G., Iademarco, M. F., Iseman, M., Olivier, K., Ruoss, S., Von Reyn, F. C., Wallace, R. J., Winthrop, K., 2007. American Thoracic Society Documents An Official ATS / IDSA Statement: Diagnosis, Treatment, and Prevention of Nontuberculous Mycobacterial Diseases, American Journal of respiratory and Critical Care Medicine 175, 367 - 416.

[15] Hamid, M.E., Roth, A., Landt, O., Kroppenstedt, M., Goodfellow, M., Mauch, H., 2002. senegalense Strains Based on 16S-23S Ribosomal DNA Internal Transcribed Spacer Sequences, Journal of Clinical Microbiology , 40(2), 707-711.

[16] Ingen, J. Van., Lange, W. C. M., Bendien, . A.,Hoefsloot, W., Dekhuijzen, P. N. R, Boerec, M. J., Soolingen, D. W., Clinical relevance of non-tuberculous mycobacteria isolated in the Nijmegen-Arnhem region , The Netherlands., Thorax,502-506.

[17] Jarlier, V., Nikaido, H., 1994, Mycobacterial Cell Wall: Structure and role in natural resistance to antibiotics, FEMS Microbiology Lett, 123:11-8

[18] Kankya, C., Muwonge, A., Djønne, B., Munyeme, M., Opuda-Asibo, J., Skjerve, E., Oloya, J., Johansen, T. B., 2011. Isolation of non-tuberculous mycobacteria from pastoral ecosystems of Uganda: public health significance. BMC public health, 11, 320.

[19] Katale, B.Z. et al., 2014. Species diversity of non-tuberculous mycobacteria isolated from humans, livestock and wildlife in the Serengeti ecosystem , Tanzania. , pp.1-8.

[20] Katoch, V.M., 2004. Infections due to nontuberculous mycobacteria (NTM). Indian Journal of Medical Research, 120(4), pp.290304.

[21] Katoch, V.M., Parashar, D., Chauhan, D. S., Singh, D, Sharma, V. D, Gosh, S., 2007. Rapid identification of mycobacteria by gene amplification restriction analysis technique targeting 16S - 23S ribosomal RNA internal transcribed spacer \& flanking region. Indian Journal of Medical Respiratory, 155-162.

[22] Konuk, M., Korcan, E., Dulgerbaki, S., Altindis, M., 2007, Isolation and identification of Mycobacteria from raw milk samples in Afyonkarahisar district of Turkey. International Journal of Food Microbiology 115, 343-347.

[23] Lopez, F., Miley, M., Taiwo, B., 2016, Mycobacterium arupense as an Emerging cause of Tenosynovitis, Emerging infectious Diseases, 22, 559 - 560.
[24] Malama, S., Johansen, T.B., Muma, J.B., Mwanza, S., Djonne, B., Godfroid, J., 2014b, Isolation and molecular characterization of Mycobacterium bovis from Kafue lechwe (Kobus leche kafuensis) from Zambia. Trop Anim Health Prod46, 153-157.

[25] Malama, S., Muma, J., Munyeme, M., Mbulo, G., Muwonge, A., Shamputa, I.C., Djonne, B., Godfroid, J., Johansen, T.B., 2014c, Isolation and Molecular Characterization of Mycobacterium tuberculosis from Humans and Cattle in Namwala District, Zambia. Ecohealth.

[26] Malama, S., Muma, J.B., Godfroid, J., 2013, A review of tuberculosis at the wildlife-livestockhuman interface in Zambia. Infect Dis Poverty2, 13.

[27] Malama, S., Munyeme, M., Mwanza, S., Muma, J.B., 2014d, Isolation and characterization of non tuberculous mycobacteria from humans and animals in Namwala District of Zambia. BMC Res Notes 7, 622 .

[28] Munyeme, M., Muma, J.B., Samui, K.L., Skjerve, E., Nambota, A.M., Phiri, I.G., Rigouts, L., Tryland, M., 2009, Prevalence of bovine tuberculosis and animal level risk factors for indigenous cattle under different grazing strategies in the livestock/wildlife interface areas of Zambia. Trop Anim Health Prod41, 345-352.

[29] Munyeme, M., Muma, J.B., Siamudaala, V.M., Skjerve, E., Munang'andu, H.M., Tryland, M., 2010, Tuberculosis in Kafue lechwe antelopes (Kobus leche Kafuensis) of the Kafue Basin in Zambia. Prev Vet Med95, 305-308.

[30] Muwonge, A., Kankya, C., Johansen, T.B., Djonne, B., Godfroid, J., Biffa, D., Edvardsen, V., Skjerve, E., 2012, Non-tuberculous mycobacteria isolated from slaughter pigs in Mubende district, Uganda. BMC Veterinary Research 8, 52.

[31] Muwonge, A., Oloya, J., Kankya, C., Nielsen, S., Godfroid, J., Skjerve, E., Djonne, B., Johansen, T.B., 2014b, Molecular characterization of Mycobacterium avium subspecies hominissuis isolated from humans, cattle and pigs in the Uganda cattle corridor using VNTR analysis. Infect Genet Evol21, 184-191.

[32] Neonakis , I., Gitti, Z., Kontos, F., Spandidos, D., 2008, Mycobacterium aruprnse pulmonary infection: Antibiotic Resistance and restriction fragment length polymorphism analysis, Indian Journal of Medical Microbiology 28. 173 -6

[33] Panagiotou, M., Papaioannai, A. I., Kostitas, K., Paraskeya, M., Velentza, E., Kanellopoulou, M., Filaditaki., 2014. The Epidemiology of Pulmonary Nontuberculous Mycobacteria : Data from a General Hospital in Athens , Greece , 2007 - 2013, Pulmonary Medicine, 1-9. 
[34] Primm, T.P. et al., 2004. Health Impacts of Environmental Mycobacteria Health Impacts of Environmental Mycobacteria., 17(1).

[35] Ray, C. G., Ryan, K.J., ed. Sherris Medical Microbiology, $4^{\text {th }}$ Edition, McGraw-Hill, Medical. 2004.

[36] Ricketts, W.M,. Shanghnessy, T.C., Van Ingen, J., 2014. Human-to-human transmission of Mycobacterium kansasii or victims of a shared source. Europian Respiratory Journal, 44, 10821085.

[37] Thomson, R. M, Tolson, C., Carter, R., Couter, C., Huygens, F., Hargreavens., 2013. Isolation of nontuberculous mycobacteria (NTM) from household water and shower aerosols in patients with pulmonary disease caused by NTM. Journal of Clinical Microbiology, 51(9), 3006-3011.

[38] Thomson, R.M.Tolson, C., Carter, R., Couter, C., Huygens, F., Hargreavens., 2013. Factors associated with the isolation of Nontuberculous mycobacteria ( NTM ) from a large municipal water system in Brisbane, Australia, BMC Microbiology 13, 89.

[39] Tortoli, E., 2003, Impact of genotypic studies on mycobacterial taxonomy: the new mycobacteria of the 1990s. Clin Microbiol Rev16, 319-354.

[40] Velayati, A.A., Farnia, P., Mozafari, M., Malekshahian, D., Seif, S., Rahideh, S.,
Mirsaeidi, M., 2014, Molecular epidemiology of nontuberculous mycobacteria isolates from clinical and environmental sources of a metropolitan city. PLoS One9, e114428.

[41] Wang, H.X. et al., 2010. Nontuberculous mycobacteria: Susceptibility pattern and prevalence rate in Shanghai from 2005 to 2008. Chinese Medical Journal, 123(2), pp.184-187.

[42] Wayne, L.G. \& Kubica, G.P., 1986. "Family Mycobacteriaceae CHESTER 1897, 63AL"in Bergey's Manual of Systematic Bacteriology, eds. P.H.A. Sneath, N.S. Mair \& M.E.H. Sharpe J., The Williams and Wilkins Company, Baltimore, pp. 1435-1457.

[43] Weinberger, M. et al., 1992. Disseminated infection with Mycobacterium gordonae: report of a case and critical review of the literature. Clinical Infectious Diseases, 14(6), pp.122939.

[44] WHO, 2012. WorldHealth Organisation. Global tuberculosis Control WHO Report. WHO/HTM/TB/@. Geneva, Switzerland.

[45] WHO, 1991. WHO Model prescribing information: Drugs used in Mycobacterial Diseases.

[46] Wu, J., Zhang, Y., Li, J., Lin, S., Wang, L., Jiand, Y., Pan, Q., Shen, Xl., 2014. Increase in Nontuberculous Mycobacteria Isolated in Shanghai, China: Results from a PopulationBased Study, PLOS ONE, 9(10).

Citation: Ngula Monde, Musso Munyeme, Adrian Muwonge, John Bwalya Muma, Sydney Malama. NonTuberculous Mycobacteria Recovered from Suspected TB Cases in Namwala District of Zambia. ARC Journal of Clinical Case Reports. 2017; 3(2):1-7. doi:dx.doi.org/10.20431/2455-9806.0302002.

Copyright: (C) 2017 Authors. This is an open-access article distributed under the terms of the Creative Commons Attribution License, which permits unrestricted use, distribution, and reproduction in any medium, provided the original author and source are credited. 